\title{
Initial Assessment of Open Rotor Propulsion Applied to an Advanced Single-Aisle Aircraft
}

\author{
Mark D. Guynn ${ }^{1}$ \\ NASA Langley Research Center, Hampton, VA, 23681 \\ Jeffrey J. Berton ${ }^{2}$, Eric S. Hendricks ${ }^{3}$, Michael T. Tong ${ }^{4}$, and William J. Haller ${ }^{5}$ \\ NASA Glenn Research Center, Cleveland, $\mathrm{OH}, 44135$ \\ and \\ Douglas R Thurman ${ }^{6}$ \\ Army Research Lab, Cleveland, OH, 44135
}

\begin{abstract}
Application of high speed, advanced turboprops, or "propfans," to subsonic transport aircraft received significant attention and research in the 1970 s and 1980 s when fuel efficiency was the driving focus of aeronautical research. Recent volatility in fuel prices and concern for aviation's environmental impact have renewed interest in unducted, open rotor propulsion, and revived research by NASA and a number of engine manufacturers. Unfortunately, in the two decades that have passed since open rotor concepts were thoroughly investigated, NASA has lost experience and expertise in this technology area. This paper describes initial efforts to re-establish NASA's capability to assess aircraft designs with open rotor propulsion. Specifically, methodologies for aircraft-level sizing, performance analysis, and system-level noise analysis are described. Propulsion modeling techniques have been described in a previous paper. Initial results from application of these methods to an advanced single-aisle aircraft using open rotor engines based on historical blade designs are presented. These results indicate open rotor engines have the potential to provide large reductions in fuel consumption and emissions. Initial noise analysis indicates that current noise regulations can be met with old blade designs and modern, noiseoptimized blade designs are expected to result in even lower noise levels. Although an initial capability has been established and initial results obtained, additional development work is necessary to make NASA's open rotor system analysis capability on par with existing turbofan analysis capabilities.
\end{abstract}

\section{Introduction}

$\mathrm{T}$ HE Subsonic Fixed Wing (SFW) Project of NASA's Fundamental Aeronautics Program and the Environmentally Responsible Aviation (ERA) Project of NASA's Integrated System Research Program have jointly established a series of goals for future generations of subsonic transport aircraft technology. These goals are shown in Fig. 1, where "N+x" refers to the series of technology generations which emerge over time. Propulsion technology will play a critical role in reaching the goals in every generation. Engines of the future will need to have lower fuel consumption, lower noise, and emit fewer harmful emissions. Airlines, and therefore aircraft and engine manufacturers, have always had a desire to reduce fuel consumption because of its direct impact on operating cost. But because of the conservative nature of the aviation industry, a great deal of economic pressure is necessary for

\footnotetext{
${ }^{1}$ Aerospace Engineer, Aeronautics Systems Analysis Branch, Mail Stop 442, Senior Member AIAA.

${ }^{2}$ Aerospace Engineer, Multidisciplinary Design, Analysis \& Optimization Branch, MS 5-11, Senior Member AIAA.

${ }^{3}$ Aerospace Engineer, Multidisciplinary Design, Analysis \& Optimization Branch, MS 5-11.

${ }^{4}$ Aerospace Engineer, Multidisciplinary Design, Analysis \& Optimization Branch, MS 5-11.

${ }^{5}$ Aerospace Engineer, Multidisciplinary Design, Analysis \& Optimization Branch, MS 5-11.

${ }^{6}$ Aerospace Engineer, Multidisciplinary Design, Analysis \& Optimization Branch, MS 5-11.
}

1

American Institute of Aeronautics and Astronautics 
"radical" technologies to be considered. In NASA's opinion, however, the goals in Fig. 1 cannot be achieved with conservative, evolutionary technologies and concepts. As NASA works towards these goals by investing in technology research and development, numerous unconventional ideas are considered and evaluated for their potential impacts. One such unconventional concept is open rotor propulsion.

When the aviation industry faced dramatically rising fuel costs in the 1970s, the response was a national research portfolio aimed at improving aircraft fuel efficiency. ${ }^{1,2}$ One element of this research portfolio was the NASA Advanced Turboprop Project, focused on high-speed, unducted or "open rotor" propulsors. A number of open rotor concepts were developed and tested as part of this program. The program was highly successful and was awarded the Collier Trophy in 1987, but after fuel prices declined sharply there was no longer sufficient motivation to continue maturing the technology. As a result, high-speed commercial transport aircraft in service today still use ducted, turbofan engines. However, recent volatility in fuel prices and concern for aviation's environmental impact have renewed interest in unducted, open rotor propulsion for subsonic transports and revived research by NASA and a number of engine manufacturers.,

\begin{tabular}{|c|c|c|c|}
\hline \multirow{2}{*}{$\begin{array}{c}\text { TECHNOLOGY } \\
\text { BENEFITS* }\end{array}$} & \multicolumn{3}{|c|}{$\begin{array}{c}\text { TECHNOLOGY GENERATIONS } \\
\text { (Technology Readiness Level = 4-6) }\end{array}$} \\
\cline { 2 - 4 } & $\mathbf{N + 1}(\mathbf{2 0 1 5 )}$ & $\mathbf{N + 2}\left(\mathbf{2 0 2 0 ^ { * * } )}\right.$ & $\mathbf{N + 3}$ (2025) \\
\hline $\begin{array}{c}\text { Noise } \\
\text { (cum margin rel. to Stage 4) }\end{array}$ & $-32 \mathrm{~dB}$ & $-42 \mathrm{~dB}$ & $-71 \mathrm{~dB}$ \\
\hline $\begin{array}{c}\text { LTO NOx Emissions } \\
\text { (rel. to CAEP 6) }\end{array}$ & $-60 \%$ & $-75 \%$ & $-80 \%$ \\
\hline $\begin{array}{c}\text { Cruise NOx Emissions } \\
\text { (rel. to 2005 best in class) }\end{array}$ & $-55 \%$ & $-70 \%$ & $-80 \%$ \\
\hline $\begin{array}{c}\text { Aircraft Fuel/Energy Consumption } \\
\text { (rel. to 2005 best in class) }\end{array}$ & $-33 \%$ & $-50 \%$ & $-60 \%$ \\
\hline
\end{tabular}

* Projected benefits once technologies are matured and implemented by industry. Benefits vary by vehicle size and mission. $\mathrm{N}+1$ and $\mathrm{N}+3$ values are referenced to a 737-800 with CFM56-7B engines, N+2 values are referenced to a 777-200 with GE90 engines

** ERA's time-phased approach includes advancing "long-pole" technologies to TRL 6 by 2015

$\ddagger \mathrm{CO}_{2}$ emission benefits dependent on life-cycle $\mathrm{CO}_{2 \mathrm{e}}$ per $\mathrm{MJ}$ for fuel and/or energy source used

Figure 1. NASA's technology goals for subsonic transport aircraft.

Numerous studies on the benefits of open rotor engines were published in the 1980s, Refs. 5 and 6 are two of many examples. Generally, the target application for these studies was short range aircraft in the 100-150 passenger class with cruise Mach numbers less than 0.8. The fuel consumption benefit of open rotor propulsion compared to equivalent technology turbofan engines was typically found to be around $25 \%$. One of the challenges consistently identified, however, was higher noise. Interior noise was reduced to levels equivalent to aircraft of that era through use of additional acoustic treatment, at the cost of increased aircraft empty weight. Most of the studies found certification noise levels at or below Stage 3 limits (see Ref. 7 for a description of aircraft noise regulations). Although commercial transport aircraft designs with open rotor propulsion were studied extensively in the late 1970s and 1980s, the results of those studies do not necessarily remain valid today due to advances in airframe and engine technology, and changes in the regulatory and market environments into which the aircraft will be inserted. Benefits measured relative to the engines of that era are no longer valid since ducted, turbofan engines have advanced in the intervening years. Also, current and future noise regulations are stricter than those considered in the past studies. Because of the renewed interest in open rotor propulsion, the lack of publicly available up-to-date studies assessing their benefits, and NASA's focus on reducing fuel consumption, internal studies on open rotor propulsion have been initiated to inform decisions concerning research in this area.

Unfortunately, in the two decades that have passed since open rotor concepts were thoroughly investigated, NASA has lost experience and expertise in this technology area. In order for this concept to be assessed to the same level of confidence as more traditional designs, new tools and methods are needed. The first step in performing a reliable assessment of this technology is to develop and exercise the necessary analysis processes. This paper describes the initial capabilities which have been established at NASA to assess aircraft-level performance and noise for designs with open rotor propulsion and some of the initial results that have been obtained. The target application used to exercise these methods is the Boeing 737/Airbus A320 single-aisle aircraft class. The 737/A320 class of aircraft represents a significant portion of the global airline fleet, and a significant opportunity for technology 
insertion. Sixty-nine percent of the new aircraft produced over the next 20 years are projected to be in this class. ${ }^{8}$ Advances made to reduce the fuel consumption, noise, and emissions of these aircraft could provide a considerable positive contribution to the goal of minimizing the future environmental impact of aviation. A new vehicle in this size class would also be a prime candidate for open rotor propulsion.

\section{Study Objectives and Approach}

This is a preliminary study with the objective of demonstrating the ability to analytically assess the potential benefits and penalties of open rotor propulsion concepts as applied to an advanced 737/A320 replacement aircraft. This initial study is necessarily limited in detail and scope due to a lack of analysis tools to address all aspects of open rotor propulsion design, performance, and integration. Models used are approximate and the results should be viewed as preliminary while enhancements to the methods and data used to feed the processes continue. The general approach taken for this study is to develop analytical models of advanced open rotor engines, combine them with an advanced technology airframe, design the overall system to meet mission requirements and constraints, and assess the resulting noise, fuel consumption, and emission characteristics.

\section{Modeling and Analysis Methodology}

\section{A. Propulsion Modeling}

Propulsion system modeling was performed using NPSS (Numerical Propulsion System Simulation) ${ }^{9-11}$ for cycle analysis and performance and WATE (Weight Analysis of Turbine Engines) ${ }^{12-14}$ for aeromechanical design and weight estimates. Estimates for $\mathrm{NO}_{\mathrm{X}}$ emission indices were obtained from an empirical correlation representing an advanced, low $\mathrm{NO}_{\mathrm{X}}$ combustor. Reference 15 provides more details on this empirical $\mathrm{NO}_{\mathrm{X}}$ correlation, which was developed by NASA combustor technologists during the latter stages of NASA's Ultra-Efficient Engine Technology Program. Developing the capability to design and analyze open rotor configurations with NPSS was a significant task in itself. Reference 16 provides details on the basic open rotor modeling approaches that have been recently developed. Engine modeling technology assumptions were based on those used in the NASA advanced turbofan engine design studies described in Refs. 15 and 17.

\section{B. Airframe Modeling}

Previous open rotor studies have identified a number of possible airframe integration options. Reference 18 contains an excellent discussion of the various propulsion system and integration options, and the benefits and issues associated with each combination. The primary focus towards the end of the open rotor work of the 1980s was the rear-mounted pusher configuration (see Fig. 2). As detailed in Ref. 18, this integration approach is favored from the aspect of passenger accommodation (lower interior noise) and wing aerodynamics. Although there are a number of issues that would need to be addressed to make this configuration viable, such as foreign object damage (FOD) susceptibility, stability and control impacts, and wake/rotor interaction, this layout seemed to be the preferred approach during the late 1980s. Because NASA's current focus in open rotor propulsion is the counter-rotating, pusher concept and a rear-mounted installation is the most likely configuration for this propulsion system, a rear fuselage-mounted engine layout was selected for this initial study.

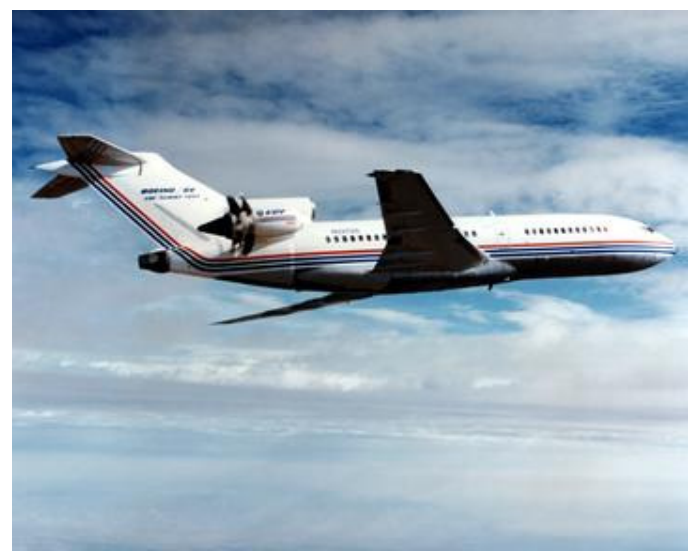

Figure 2. Rear-mounted open rotor pusher configuration, shown on Boeing 727 test vehicle. 
Development of a suitable airframe model began with modeling of the rear-engined, single-aisle MD-90-30 configuration in the NASA aircraft sizing and synthesis code, FLOPS ${ }^{19}$ using publicly available data on weights and performance ${ }^{20,21}$ and a NASA-developed model representative of the International Aero Engines V2525-D5 engine. The wing and fuselage structural weight estimates of FLOPS were replaced with estimates from PDCYL ${ }^{22}$, which offers a less empirical, more analytical weight estimation methodology. Using geometry, weight (maximum gross weight and maximum landing weight), and mission data from Ref. 20, and wing weight and fuselage weight predictions from PDCYL, FLOPS predicts an operating empty weight (OEW) of 91,470 lb compared to the manufacturer's reported value of $88,175 \mathrm{lb}$. Although this represents only a $3.5 \%$ difference between predicted and actual weight, the FLOPS model was calibrated to the actual value. The model was calibrated by applying an overall reduction factor on empty weight since weight data were not available to compare predicted and actual weights at the component level. A point on the range-payload diagram of Ref. 20 was used to calibrate the range performance in the FLOPS model. Assuming 31,000 lb of payload (155 passengers) and a takeoff gross weight of 156,000 lb, reported range capability for the MD-90-30 is approximately $2040 \mathrm{~nm}$. The initial FLOPS-predicted range performance was significantly higher. There are a number of possible sources for error in the FLOPS-predicted range, including using a different mission profile (cruise Mach and altitude, reserve mission assumptions), discrepancy in predicted and actual aerodynamic performance, and discrepancies between the NASA engine model and actual engine fuel consumption characteristics. Without additional data in one of these areas, it is impossible to determine the underlying source of the model discrepancies. Because the FLOPS predicted cruise aerodynamic efficiency did not seem optimistic and the cruise thrust specific fuel consumption (TSFC) seemed low compared to other engines of this class, range performance of the model was calibrated to the published value by only adjusting the V2525-D5 engine model. In reality, the error is likely due to a combination of factors.

A series of modification were necessary to progress from a MD-90-30 like FLOPS model to an appropriate advanced technology airframe model suitable for the open rotor engines. These steps are summarized in Fig. 3 and described in more detail below.

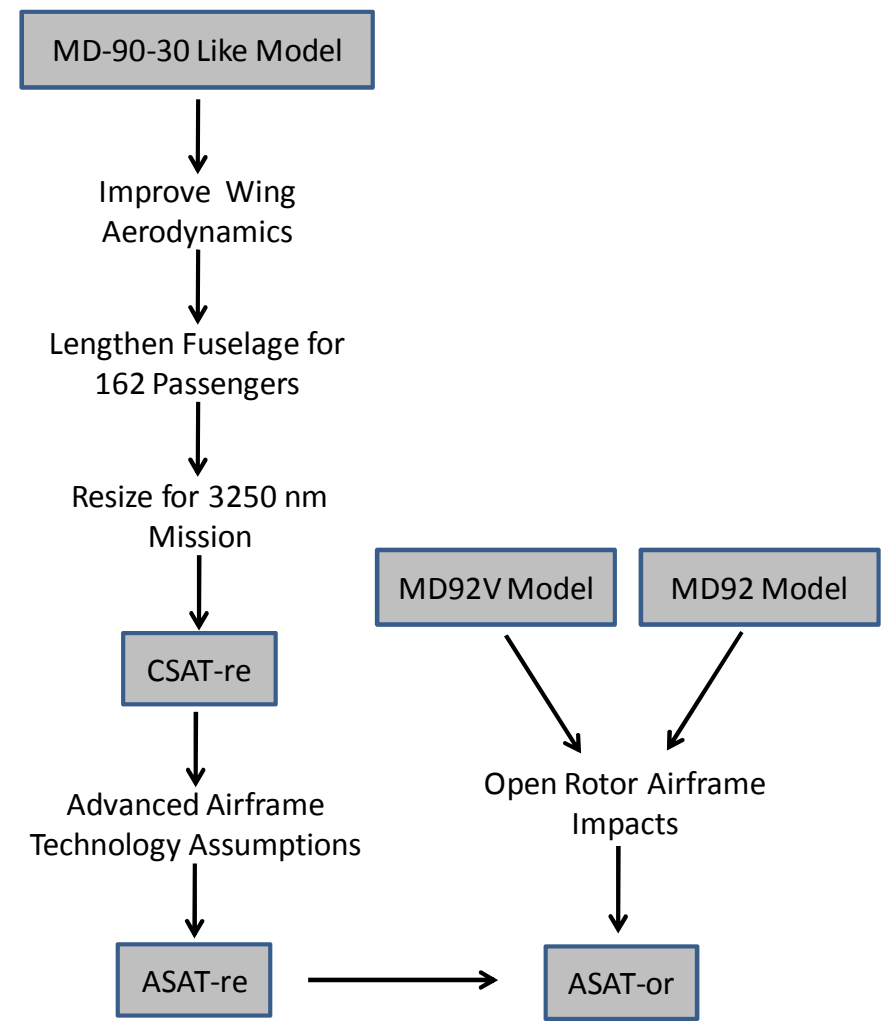

Figure 3. Process used to model advanced technology airframe suitable for open rotor propulsion.

Previous NASA studies of propulsion options for 737/A320 replacement designs have used a Boeing 737-800 based airframe model and design mission. ${ }^{15,17}$ The MD-90-30-based model described above differs from the 737 800 -based model in a number of respects. Of critical importance in developing a consistent technology baseline is 
the level of airfoil design technology for the MD-90-30 wing. The MD-90-30 uses the same wing design as the older MD-80 series. This 1980 s technology is not as advanced as the newer 737-800 wing (1998 entry-into-service). Although the exact difference in aerodynamic design between the 737-800 and MD-90-30 is not known in the public domain, there is some indication of the potential gap in aerodynamic efficiency provided by comparing the current 737 design to older models. One source indicates maximum $\mathrm{M}^{*}(\mathrm{~L} / \mathrm{D})$ (Mach number times lift-to-drag ratio) of the 737-700 is $16 \%$ higher than the equivalent size, older generation 737-300 design. ${ }^{*}$ In order to advance the MD-9030 like airframe model to late 1990s technology levels, FLOPS aerodynamic factors were adjusted to provide a similar improvement in aerodynamic efficiency. The takeoff and landing aerodynamic performance was also modified. A model of the 737-800 low speed performance was used as a rough approximation for the notional, updated version of the MD-90-30. Changes were also made to the MD-90-30 design mission to reflect performance enhancements projected for future advanced aircraft in this vehicle class. Although based on desired future capabilities, this design mission (162 passengers, mixed class, $3250 \mathrm{~nm}$ ) was also applied to the older technology baseline model to enable a consistent comparison with the advanced study vehicles. Since the MD-90-30 fuselage only accommodates 158 passengers in mixed class seating, the fuselage length was slightly increased to accommodate an additional row of seats. Wing area was increased corresponding to the higher gross weight needed to meet the design mission. The resulting airframe, referred to as CSAT-re (Current technology Single-Aisle Transport-rear engine), represents a model of the MD-90-30 updated to late 1990s entry-into-service technology levels and re-sized to perform the study design mission.

The Advanced Single-Aisle Transport-rear engine (ASAT-re) airframe model is a derivative of the CSAT-re model intended to be representative of a potential advanced technology single-aisle replacement aircraft. The primary airframe technology advancement assumed is extensive use of composite materials for the airframe structure. The composite construction is assumed to result in a $15 \%$ reduction in weight of the wing, fuselage, and empennage compared to the metal construction used for the CSAT-re airframe. This weight reduction represents an assumed benefit for future composite structures and is not necessarily a reflection of the benefit composite materials have provided to date. Other minor technology improvements include an increase in hydraulic pressure to $5000 \mathrm{psi}$, and a $1 \%$ reduction in drag associated with a variable camber trailing edge and general drag clean-up. The basic geometry parameters were not changed from the CSAT-re model.

The MD-90-30-based ASAT-re layout is generally compatible with an open rotor propulsion system, and in fact, open rotor propulsion was considered during design of the MD-90 family. Reference 23 describes the design of both turbofan and open rotor configurations for the MD-90 family and details the modifications to the turbofan version that are necessary to accommodate an open rotor engine. To approximate the impact of those modifications, the MD-92 configurations detailed in Ref. 23 were examined and modeled in FLOPS. Reference 23 discusses several differences between the MD-92 (open rotor) and MD-92V (turbofan) airframe designs necessitated by the integration of the open rotor system. The fuselage weight is higher due to additional acoustic treatment for reduced interior noise, sonic fatigue treatment of the aft fuselage structure, and structural treatments to reduce vibrations. Hydraulic system weight is increased by an additional hydraulic system dedicated to the tail control surfaces. A center-of-gravity management system is needed to deal with stability and control issues introduced by the heavier aft engine weight and higher engine thrust line. The system-level impact of these differences, plus the higher weight of the open rotor engine, was a $4200 \mathrm{lb}$ increase in empty weight. Since detailed weight increments were not provided in Ref. 23, this overall weight increase was allocated in an approximate manner to each of the above areas to develop a FLOPS model of the MD-92 from a MD-92V FLOPS model. The adjustments necessary to convert from the MD-92V (turbofan) to the MD-92 (open rotor) configuration were then applied to the ASAT-re model described above to develop the ASAT-or (Advanced Single-Aisle Transport-open rotor) model for use in the open rotor aircraft analysis. The nominal ASAT-or configuration is shown in Fig. 4.

\footnotetext{
"Based on graph presented in the "Flight Controls" section of "The Boeing 737 Technical Site" http://www.b737.org.uk/flightcontrols.htm. Accessed on 4/11/2011.
} 


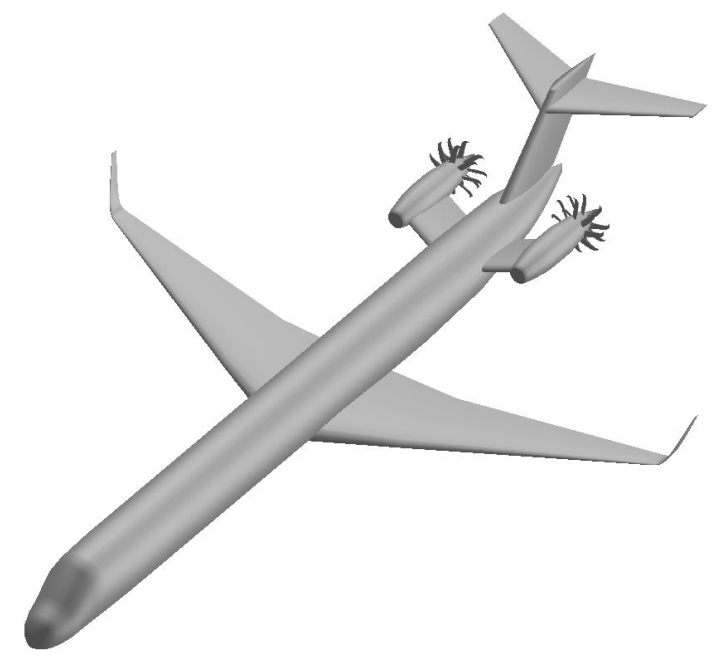

Figure 4. Basic Advanced Single-Aisle Transport configuration with rear-mounted open rotor engines. (ASAT-or).

\section{Noise Analysis}

Prediction of open rotor FAR Part $36^{7}$ certification noise is of critical importance in understanding the trades between lower fuel consumption and higher noise. Noise prediction is also an area with significant challenges. A number of counter-rotating open rotor source noise prediction methods were developed during NASA's previous studies of open rotors in the 1970s and 1980s. Perhaps the most promising of these methods are the semi-empirical codes described in Refs. 24 and 25, which have recently been revived and validated on modern computing platforms. However, these methods predict only rotor-rotor discrete interaction tones and are incapable of evaluating rotor broadband noise. They are also not capable of evaluating the noise of rotors having advanced, low-noise design features. Open rotor propulsors are now designed using modern, 3D aerodynamic analytical tools and advanced rotors will employ low-noise features, some of which have been made public and others that are still companyproprietary. Noise mitigation strategies that have been made public ${ }^{26}$ include aeroacoustic blade shaping, blade pitch angle and rotational speed optimization, increased blade counts, low disk loading, rotor-rotor spacing and pylonrotor spacing optimization, aft rotor clipping, and pylon wake reduction. Because of the shortcomings of the semiempirical methods, a system-level noise prediction method has been developed which uses noise data measured from scale model open rotor test articles.

\section{Open Rotor Source Noise Model}

Testing of various open rotor designs is underway in NASA Glenn's experimental facilities as part of an ongoing NASA-General Electric collaborative partnership. ${ }^{27}$ Low-speed aerodynamic and acoustic tests were conducted in 2009 and 2010 in the Glenn 9- by 15-ft Low Speed Wind Tunnel, while (at this writing) high-speed aerodynamic testing is underway in the Glenn 8- by 6-ft tunnel. The open rotor acoustic data used to illustrate the certification noise calculation process in this paper was collected from General Electric's F31/A31 rotor blade set. ${ }^{28}$ The approximately one-fifth scale F31/A31 rotor set - often referred to as the "historical blade set" - dates to the Advanced Turboprop Project ${ }^{29,30}$ of the 1980s. It is a non-proprietary, unducted fan representative of an early 1990s technology level, the acoustic data for which may be published in the open literature. Additional details of the rotor design may be found in Ref. 31. Advanced design, proprietary rotor sets have also been tested at NASA Glenn, and will be used for NASA assessments of open rotor aircraft in the future. Although the advanced rotor sets may be more representative of what may one day fly, the F31/A31 historical blade set data is sufficiently representative to develop and demonstrate the system-level noise analysis process.

The experimental set-up is illustrated in Fig. 5, showing the F31/A31 open rotor source and the linear microphone array. The microphone traverse array is located $60 \mathrm{in.} \mathrm{from} \mathrm{the} \mathrm{centerline} \mathrm{of} \mathrm{the} \mathrm{rotor} \mathrm{model.} \mathrm{Each}$ tunnel "reading" consists of narrowband spectral density levels taken at 18 sideline microphone locations with frequencies ranging from zero to $100 \mathrm{kHz}$ at frequency intervals of $12.2 \mathrm{~Hz}$. Data with the open rotor model operating at various shaft speeds were collected. Both rotors always operated at identical shaft speeds. Tests were also conducted to estimate the facility's tare background noise levels with no power supplied to the open rotor test article and with no blades attached. 

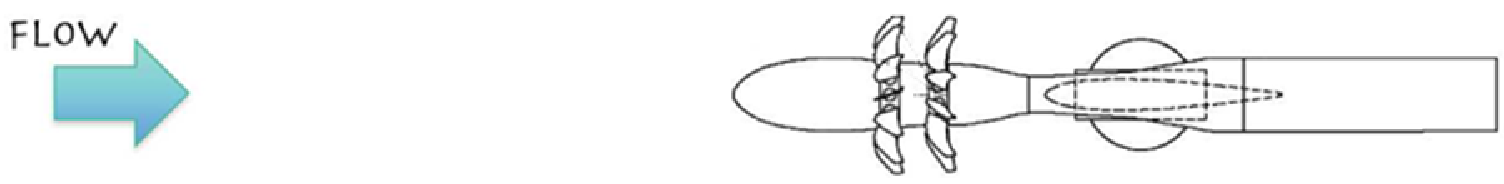

Figure 5. F31/A31 open rotor test article and linear microphone array in the NASA Glenn 9- by 15-ft Low Speed Wind Tunnel (Diagram courtesy of Edmane Envia, NASA Glenn Research Center).

The geometric sideline microphone array angles $\left(\theta_{G}\right)$ range from $18 \mathrm{deg}$ to $140 \mathrm{deg}$, where the zero reference of $\theta_{G}$ is directly upstream. Emission yaw angles $\left(\theta_{E}\right)$ are computed from the geometric sideline microphone array angles using the relation $\theta_{E}=\theta_{G}-\sin ^{-1}\left[M_{\text {Tunnel }} \sin \theta_{G}\right]$, where the tunnel Mach number $M_{\text {Tunnel }}$ in the experiments is 0.20 . Data were also collected for $M_{\text {Tunnel }}=0.18$ and 0.22 , but they are not used in this assessment.

The spectral density levels are corrected by the facility's data acquisition software to lossless, freefield conditions using an atmospheric attenuation model. The spectral density levels are further corrected for spherical spreading from the microphone's constant sideline distance to a 1-foot constant radius arc. The measured, modelscale, narrowband data must be manipulated in several ways in order to properly compute certification noise for an actual, full-scale aircraft. After being corrected by the facility's data acquisition software to freefield, lossless spectral density levels on a 1-foot arc, the spectra are modified further by applying the following corrections: removal of background facility noise, conversion to static conditions, conversion to flight conditions, conversion to full scale, and conversion to $1 / 3^{\text {rd }}$ octave band center frequencies. Details on the approaches used for these corrections are contained in Ref. 32 .

Several of the correction processes are illustrated in Fig. 6 using a sample spectrum taken from a microphone reading in the forward quadrant. A one-foot-arc, lossless, narrowband spectrum with facility noise removed is shown by the black line in Fig. 6 (left). This spectrum has an emission yaw angle of 24 degrees from the inlet, the tunnel Mach number is 0.20 , and the F31/A31 open rotor test article is operating at a corrected shaft speed of 6300 $\mathrm{rpm}$. Although noise measurements are available up to $100 \mathrm{kHz}$, only lower-frequency data are plotted. When flight condition scaling is applied (scaling to a flight Mach of 0.26 at $1000 \mathrm{ft}$ is shown in the figure), the spectrum shifts to higher amplitudes and frequencies to the condition represented by the red line in the figure. Opposite shifting behavior occurs for spectra in the aft quadrant. Scaling from experimental tunnel conditions to appropriate, simulated flight conditions can result in changes of several decibels in the fore or aft quadrants and is thus an important processing step.

When the linear and area scale factors are applied to convert from model scale to full scale, the spectrum shifts to much higher amplitudes and lower frequencies represented by the blue lines in both sides of the figure. At one-fifth scale, the inaudible sound pressure levels measured at frequencies of about $50 \mathrm{kHz}$ are shifted to the audible, regulated range used to estimate noise certification levels.

The $1 / 3^{\text {rd }}$ octave band sound pressure levels are plotted in Fig. 6 (right). The fundamental blade passage frequency tones for the front and aft rotors are labeled "1f" and "1a" in the figure, respectively. Several higher-order rotor-rotor discrete interaction tones are also noted in the figure. Seldom do any of the interaction tones above the $2 \mathrm{f}+2 \mathrm{a}$ tone contribute significantly to the overall sound pressure level. The reasoning behind the frequency "coarsening" from the narrowband to the $1 / 3^{\text {rd }}$ octave band is that the resulting spectra become much easier to manipulate and store. Many of the rotor-rotor interaction tones lie within a single frequency interval, such that a single $1 / 3^{\text {rd }}$ octave band sound pressure level may incorporate two (or more) tones, particularly at higher frequencies since the scale is logarithmic. In an open rotor aircraft noise certification test (or a simulation of one), the acoustic spectra observed by the microphone will fluctuate significantly when tones move from one frequency interval into another as the aircraft-observer geometry changes, and convective amplification and Doppler effects come into play. This will lead to irregular tone-weighted, perceived noise level (PNLT) time histories as the airplane traverses a path 
relative to its certification observers. This is an effect observed in large turboprops in the transport category as well, but it should be even more pronounced for an open rotor airplane with its much more complex tonal content.

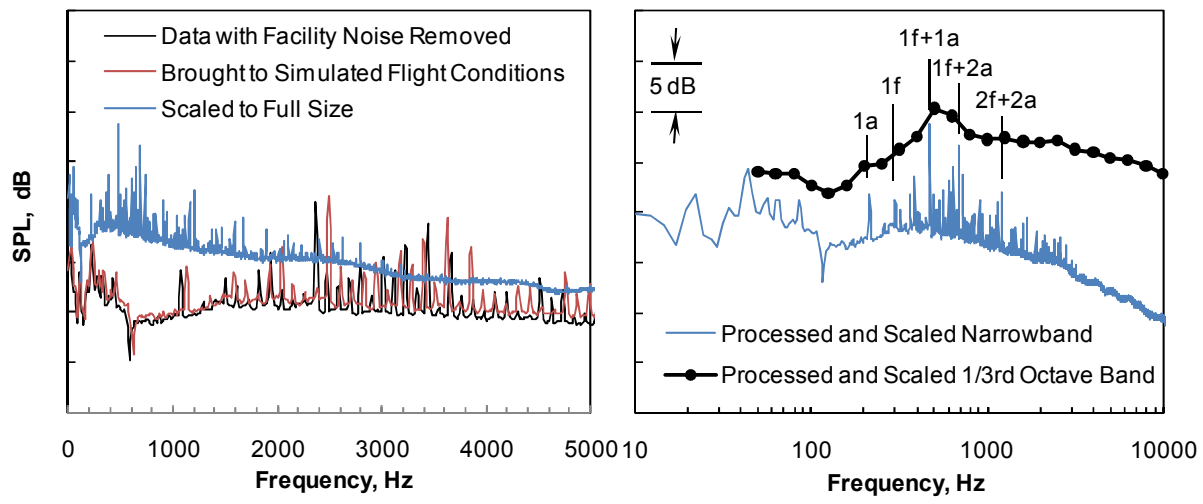

Figure 6. Sample open rotor scale-model narrowband spectrum conversion to full size (left); and conversion from full-scale narrowband spectrum to standard $1 / 3^{\text {rd }}$ octave band center frequencies (right).

\section{System-Level Noise Prediction}

The Aircraft Noise Prediction Program (ANOPP, Release Level 29) ${ }^{33,34}$ is a systems-level code used in this study to compute certification noise for the open rotor airplanes. The center frequency basis for ANOPP is the $1 / 3^{\text {rd }}$ octave band. The scaled $1 / 3^{\text {rd }}$ octave band open rotor spectra described above are fed into ANOPP via its Acoustics Data Module $\left(\mathrm{ACD}^{35}\right)$. ACD is an ANOPP utility that allows user-supplied spectra to be fed into a certification simulation in lieu of using ANOPP's own, built-in, source noise prediction modules.

An airplane model with appropriate low-speed aerodynamics, weight, and propulsion performance data is necessary to model the takeoff and approach trajectories needed for aircraft certification predictions. The airplane is modeled using the FLOPS computer program as described above. FLOPS computes detailed, low-speed takeoff and landing profiles using a built-in, time-stepping trajectory analysis module. Compliance with the airworthiness requirements described in Parts 36 and 25 of the Federal Aviation Regulations (Refs. 7 and 36, respectively) is observed. Vector geometry analyses for the airplane relative to the three certification microphone measurement locations - shown in Fig. 7 - are performed within ANOPP as functions of source time. The spectra are then propagated to the three certification observers on the ground in accordance with the specifications for certification measurements. Noise propagation effects accounted for include spherical spreading, Doppler shift and convective amplification, atmospheric attenuation within a layered atmosphere, ground reflections based on data for grasscovered ground, and extra ground attenuation. More complex propagation phenomena such as scattering, weather effects, and terrain are not modeled. (Note: If tones under $800 \mathrm{~Hz}$ are propagated to an observer, Part 36 regulations permit them to be ignored - provided they can be shown to be unrelated to engine source noise - since they may be artifacts of ground reflections. Tones under $800 \mathrm{~Hz}$ are very common, however, for an open rotor propulsor, as can be seen in the right hand graph of Fig. 6 . Thus, unlike most turbofan engine certification modeling, tones under 800 $\mathrm{Hz}$ are not ignored in this simulation and they do contribute to the PNLT.)

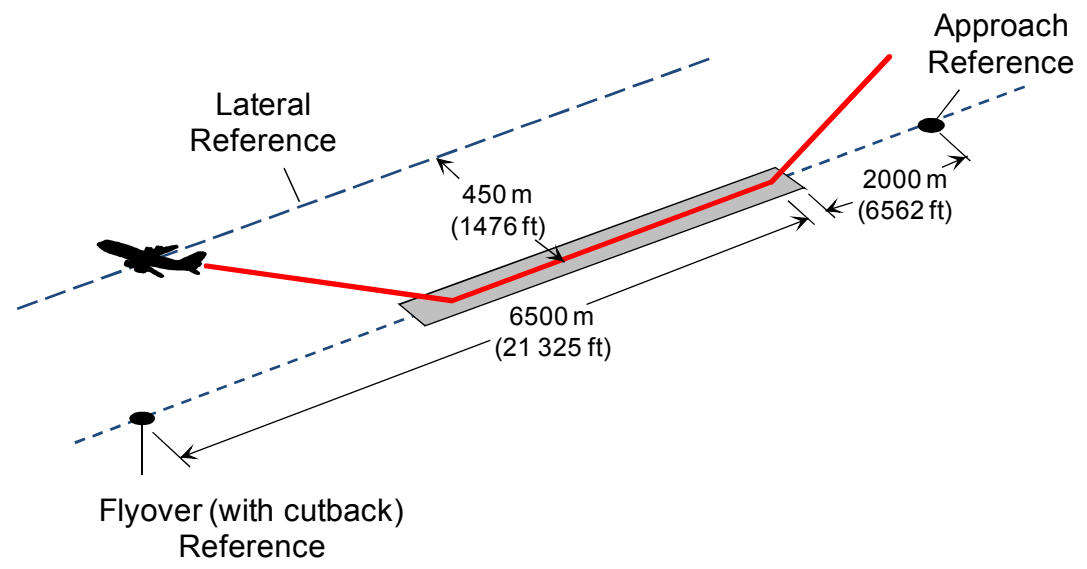

Figure 7. Observer arrangement relative to hypothetical combined takeoff and landing aircraft trajectories. 
From the propagated spectra, ANOPP computes several noise metrics of interest as functions of observer time. The Effective Perceived Noise Level (EPNL) certification noise metric is computed from the noise-time history at each observer as prescribed in Ref. 7.

\section{Initial Analysis Results}

\section{A. Engine Design}

Two different types of open rotor engine designs were modeled - geared and direct drive. The direct drive configuration is representative of the "Unducted Fan," or UDF, GE36 engine configuration developed by General Electric in the $1980 \mathrm{~s} .^{37}$ In this concept the rotor blades are directly connected to counter-rotating power turbine spools. In the geared design, the power turbine and counter-rotating rotors are connected through a speed reduction gearbox. Both engines were designed for the same thrust requirements: 4,600 lb at top-of-climb conditions $(\mathrm{M}=0.72$, $35,000 \mathrm{ft})$ and $17,500 \mathrm{lb}$ at hot day rolling takeoff $(\mathrm{M}=0.25, \mathrm{SL})$. As detailed in Ref. 16, the rotor performance maps used to develop these engine models were based on the F7/A7 rotor set designed in the 1980s and used on the GE36 UDF demonstrator. These performance maps may not be representative of the performance of newer blade designs. General characteristics of the resulting engines are shown in Table 1, compared to NASA's model of the V2525-D5 turbofan, and the open rotor engines are shown graphically in Fig. 8. The expected efficiency benefits of the advanced open rotor architecture are clearly evident in Table 1 . At the Mach=0.72, 35,000 ft top-of-climb point, the open rotor engines have approximately 29\% lower TSFC than NASA's V2525-like model. This condition is the aerodynamic design point for the F7/A7 blades and the open rotor engine cycles; whereas the V2525 is actually designed for a slightly higher Mach number. The very large reduction in TSFC for the advanced open rotor engines is from a combination of advances in the engine core as well as the higher propulsive efficiency of the open rotor. The improvement relative to an advanced turbofan with equivalent core technology would, therefore, be less.

The reduction in TSFC is even higher for the SLS and rolling takeoff conditions, $48 \%$ and $45 \%$ respectively. This should lead to much lower fuel consumption and emissions in the airport terminal area. Landing-Takeoff (LTO) $\mathrm{NO}_{\mathrm{X}}$ characteristics are presented in Table 1 in terms of the regulated parameter, " $\mathrm{D}_{\mathrm{p}} / \mathrm{F}_{\mathrm{oo}}$ " where $\mathrm{D}_{\mathrm{p}}$ is the grams of $\mathrm{NO}_{\mathrm{X}}$ emitted over a standard LTO cycle (by a single, uninstalled engine) and $\mathrm{F}_{\mathrm{oo}}$ is the rated output at SLS conditions in kilonewtons. This parameter is defined by the International Civil Aviation Organization (ICAO) and used in FAR Part 34 for engine certification. ${ }^{38}$ Reduction in $\mathrm{D}_{\mathrm{p}} / \mathrm{F}_{\mathrm{oo}}$ is on the order of $80 \%$ compared to the V2525D5. This reduction comes from a combination of lower $\mathrm{NO}_{\mathrm{X}}$ emission indices (grams of $\mathrm{NO}_{\mathrm{X}}$ emitted from the engine per kilogram of fuel consumed by the engine), due primarily to an advanced lean combustor, and lower fuel flow (higher efficiency) at the ICAO-defined LTO operating points.

The reduction in TSFC and LTO $\mathrm{NO}_{\mathrm{X}}$ does not come without penalty, however. Despite the use of advanced materials in the open rotor engines, the thrust-to-weight ratio of the open rotor engines is actually lower than for the older technology V2525-D5 turbofan. The direct drive open rotor engine has the lowest T/W, approximately $17 \%$ lower than the V2525-like model at the top-of-climb conditions. The T/W of the geared open rotor engine at top-ofclimb is approximately $15 \%$ lower than the V2525-like model. The benefit of the large TSFC reduction to total aircraft fuel consumption would be offset somewhat by the lower engine thrust-to-weight, as well as the additional airframe weight associated with accommodating open rotor propulsion. 
Table 1. General Engine Characteristics

\begin{tabular}{|c|c|c|c|}
\hline & V2525 Turbofan Model & Direct Drive Open Rotor & Geared Open Rotor \\
\hline Overall Length, $\mathrm{ft}$ & 18.3 & 15.6 & 17.7 \\
\hline Nacelle Diameter, $\mathrm{ft}$ & 8.0 & 5.5 & 5.1 \\
\hline Rotor Diameter, ft (front / rear) & $\mathrm{N} / \mathrm{A}$ & $10.9 / 9.9$ & $10.9 / 9.9$ \\
\hline \multicolumn{4}{|l|}{ Thrust, lb (TSFC, lb/(lb-h)) } \\
\hline Sea Level, Static & $25,000(0.325)$ & $22,120(0.169)$ & $22,140(0.167)$ \\
\hline $\begin{array}{l}\text { Rolling Takeoff } \\
(\mathrm{M}=0.25 ; \mathrm{SL})\end{array}$ & $24,400(0.453)$ & $17,500(0.252)$ & $17,500(0.249)$ \\
\hline $\begin{array}{r}\text { Top-of-Climb } \\
(\mathrm{M}=0.72 ; 35,000 \mathrm{ft}) \\
\end{array}$ & $5480(0.552)$ & $4,600(0.394)$ & $4,600(0.390)$ \\
\hline Engine+Nacelle Wt., lb & 7900 & 8040 & 7840 \\
\hline Engine T/W (SLS / Top-of-Climb) & $3.16 / 0.69$ & $2.75 / 0.57$ & $2.82 / 0.59$ \\
\hline \multicolumn{4}{|l|}{$\begin{array}{l}\text { LTO Fuel Flow }(\mathrm{kg} / \mathrm{s}) \\
\left(N O_{X} \text { Emission Index }(\mathrm{g} / \mathrm{kg})\right)\end{array}$} \\
\hline Take-off & $\begin{array}{l}1.053 \\
(26.5) \\
\end{array}$ & $\begin{array}{l}0.452 \\
(11.1) \\
\end{array}$ & $\begin{array}{l}0.448 \\
(11.1) \\
\end{array}$ \\
\hline Climb Out & $\begin{array}{l}0.880 \\
(22.3)\end{array}$ & $\begin{array}{r}0.369 \\
(6.9) \\
\end{array}$ & $\begin{array}{r}0.365 \\
(6.9) \\
\end{array}$ \\
\hline Approach & $\begin{array}{r}0.319 \\
(8.9) \\
\end{array}$ & $\begin{array}{l}0.119 \\
(9.0)\end{array}$ & $\begin{array}{l}0.118 \\
(9.0)\end{array}$ \\
\hline Idle & $\begin{array}{c}0.128 \\
(4.7) \\
\end{array}$ & $\begin{array}{r}0.043 \\
(5.0) \\
\end{array}$ & $\begin{array}{r}0.043 \\
(5.0) \\
\end{array}$ \\
\hline LTO $\mathrm{NO}_{\mathrm{X}}, \mathrm{D}_{\mathrm{p}} / \mathrm{F}_{\mathrm{oo}}(\mathrm{g} / \mathrm{kN})$ & 56.20 & 11.57 & 11.44 \\
\hline
\end{tabular}

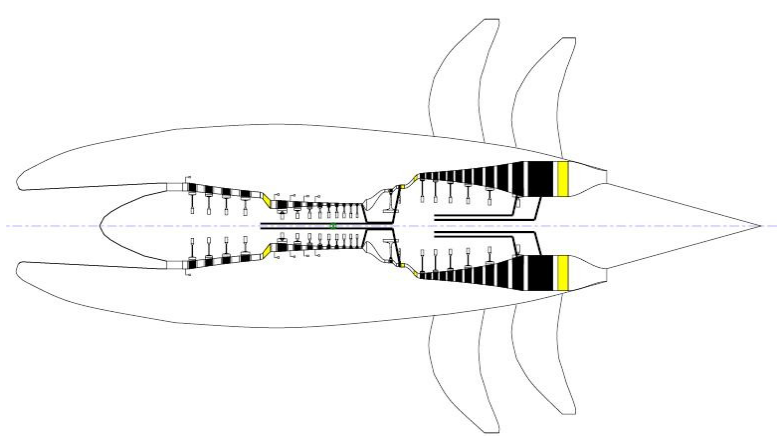

a) Direct Drive.

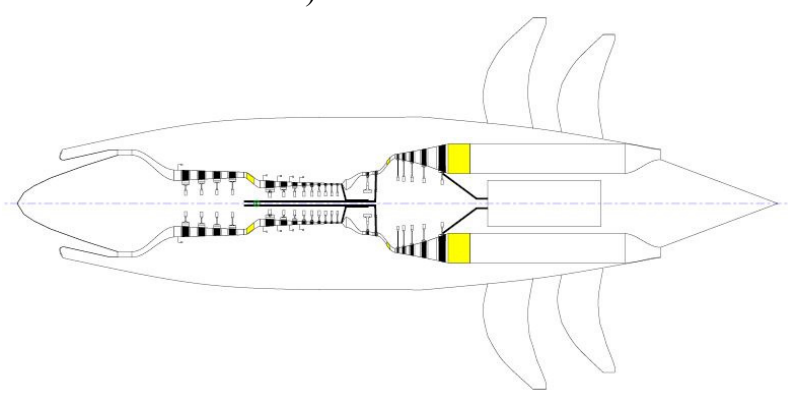

b) Geared.

Figure 8. Open rotor engine architectures: a) Direct Drive, b) Geared.

10

American Institute of Aeronautics and Astronautics 


\section{B. Aircraft Sizing and Performance}

The open rotor engines described above were combined with the ASAT-or airframe model to determine overall aircraft performance. Each configuration was sized to meet the same mission requirements: 162 passengers $(32,400$ lb), $3250 \mathrm{~nm}$ range, cruise Mach of 0.72. Although current vehicles in this size class have cruise Mach numbers of around 0.78 , this Mach number was chosen to be consistent with the F7/A7 blade design conditions. Higher cruise Mach numbers have been targeted with more recent blade designs. Wing area and engine thrust were optimized to meet the mission requirements with minimum gross weight, subject to constraints such as takeoff field length, second segment climb gradient, approach speed, landing field length, missed approach climb gradient, rate-of-climb at initial cruise altitude, and wing fuel volume. The characteristics of the resulting vehicles for each of the advanced engines are summarized in Table 2. Also included for comparison are results for the CSAT-re baseline technology airframe combined with the NASA V2525-D5-like engine model and sized for the same mission requirements. This vehicle is referred to as "1990s Technology Baseline." Weight, fuel consumption, and $\mathrm{NO}_{\mathrm{X}}$ emission results are also presented graphically in Fig. 9.

\section{Table 2. Aircraft Sizing Results}

\begin{tabular}{|l|c|c|c|}
\cline { 2 - 4 } \multicolumn{1}{l|}{} & $\begin{array}{c}\text { 1990s Tech. } \\
\text { Baseline }\end{array}$ & $\begin{array}{c}\text { ASAT-or } \\
\text { Direct OR }\end{array}$ & $\begin{array}{c}\text { ASAT-or } \\
\text { Geared OR }\end{array}$ \\
\hline OEW, lb & 94580 & 84940 & 84175 \\
\hline Mission Fuel, lb & 49360 & 29140 & 28780 \\
\hline Payload Weight, lb & 32400 & 32400 & 32400 \\
\hline Ramp Weight, lb & 176350 & 146480 & 145350 \\
\hline Wing Area, ft ${ }^{2}$ & 1540 & 1320 & 1300 \\
\hline W/S, lb/ft ${ }^{2}$ & 115 & 111 & 112 \\
\hline Thrust (SLS), lb & 25190 & 21200 & 21160 \\
\hline T/W (takeoff) & 0.286 & 0.289 & 0.291 \\
\hline Takeoff field length, ft & 7000 & 6630 & 6620 \\
\hline Landing field length, ft & 5790 & 5670 & 5690 \\
\hline $\begin{array}{c}\text { Cruise Range Factor } \\
\text { V*(L/D)/TSFC, nm }\end{array}$ & 12610 & 18270 & 18370 \\
\hline Block Fuel, lb & 41740 & 24750 & 24440 \\
\hline Total NO , lb & 255 & 150 & 148 \\
\hline LTO NO, lb per cycle & 27.8 & 4.8 & 4.7 \\
\hline
\end{tabular}




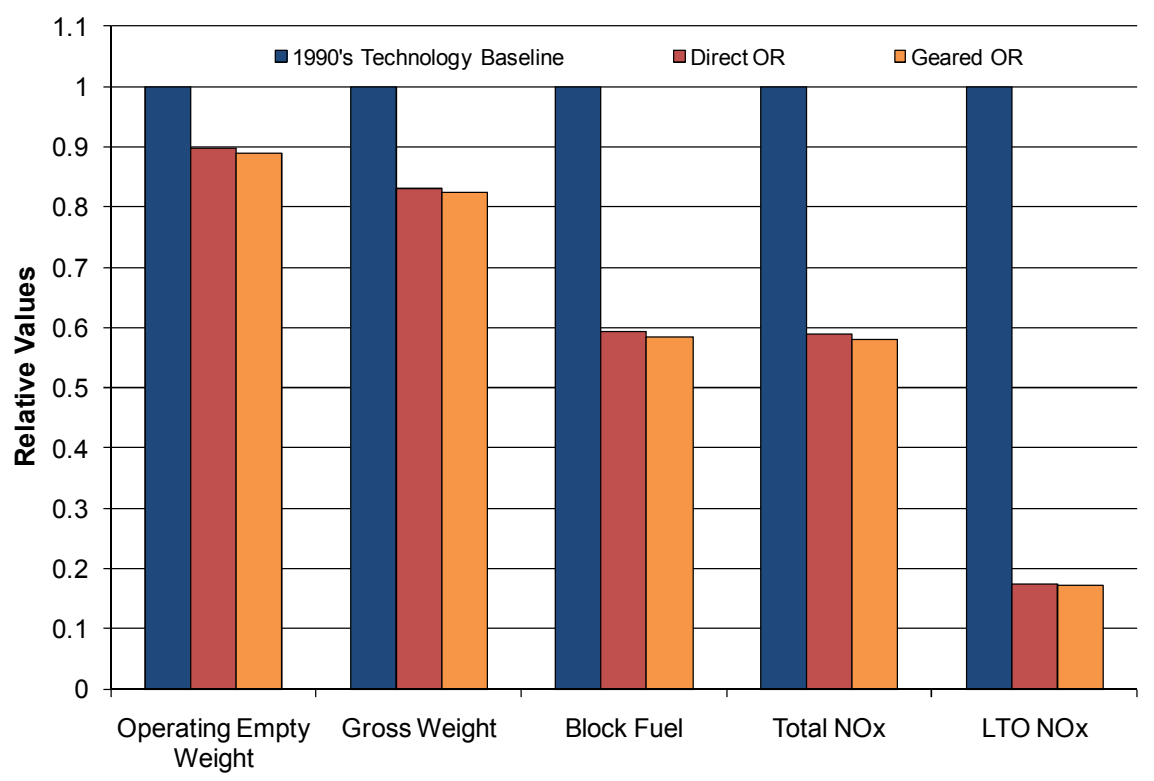

Figure 9. Advanced open rotor vehicle weight, fuel, and emissions relative to 1990 s technology baseline.

As evident in Table 2 and Fig. 9, both advanced open rotor configurations have weight, fuel consumption, and $\mathrm{NO}_{\mathrm{X}}$ emissions benefits over the 1990s technology baseline configuration. The geared design appears slightly better than the direct drive approach. However, the magnitude of the difference is insignificant for the level of analysis conducted. Empty weight reductions for the advanced configurations are relatively modest, mainly reflecting the benefits of a composite airframe and the cascading effects of a reduction in fuel weight. Relative to the 1990s baseline, fuel consumption benefits are over $40 \%$. This reduction is from a combination of advanced airframe technology, advanced engine core technology, and the open rotor architecture. To determine the true fuel consumption benefits of the open rotor architecture, comparison needs to be made to an equivalent technology turbofan configuration. Such a comparison is part of planned future open rotor assessment work. The reductions in total $\mathrm{NO}_{\mathrm{X}}$ emissions compared to the baseline are similar to the reductions in fuel consumption. $\mathrm{LTO} \mathrm{NO}_{\mathrm{X}}$ emissions are greatly reduced for the advanced configurations. The landing-takeoff cycle $\mathrm{NO}_{\mathrm{X}}$ can be expressed in a number of different ways. Values for the regulated engine parameter, " $\mathrm{D}_{\mathrm{p}} / \mathrm{F}_{\mathrm{oo}}$ " were given in Table 1 . The $\mathrm{D}_{\mathrm{p}} / \mathrm{F}_{\mathrm{oo}}$ emission parameter alone does not account for differences in engine weight and performance which can lead to differences in the required thrust level $\left(\mathrm{F}_{\mathrm{oo}}\right)$ when the engine is integrated into an overall aircraft design. The LTO $\mathrm{NO}_{\mathrm{X}}$ emissions presented in Table 2 and Fig. 9 are the estimated total $\mathrm{NO}_{\mathrm{X}}$ emissions produced during the landingtakeoff cycle. This value is derived by multiplying the ICAO $D_{p} / F_{o o}$ parameter by the total engine thrust. With lower $\mathrm{D}_{\mathrm{p}} / \mathrm{F}_{\mathrm{oo}}$ and lower sea-level static thrust, $\mathrm{NO}_{\mathrm{x}}$ emitted by the open rotor advanced configurations over a standard landing-takeoff cycle is less than one-fifth of the amount emitted by the baseline.

\section{Certification Noise}

To compute open rotor certification noise levels, the scaled acoustic data described previously are used to generate spectra at half-second time intervals along the aircraft trajectory. The spectra are propagated to each observer, and the overall sound pressure level (OASPL) and PNLT noise-time histories are computed. Results are plotted in Fig. 10, Fig. 11, and Fig. 12 for the approach, lateral, and flyover observers, respectively. Observer time relative to the point of brake release (or touchdown) is used as the independent parameter in each figure. The OASPL metric is shown on the left in each figure because of its simplicity and its ability to clearly show the relatively smooth rise and fall of each noise source over time. The PNLT metric - shown on the right in each figure - has qualities that capture level, frequency weighting, and tone annoyance penalties. Its time histories are therefore much more irregular than the OASPL histories: as the airplane approaches and recedes, Doppler and convective amplification effects influence the PNLT metric's frequency-weighting and tone penalties. Only the PNLT-time histories within an integration region of $10 \mathrm{PNdB}$ from the maximum PNLT are used to compute EPNLs. 

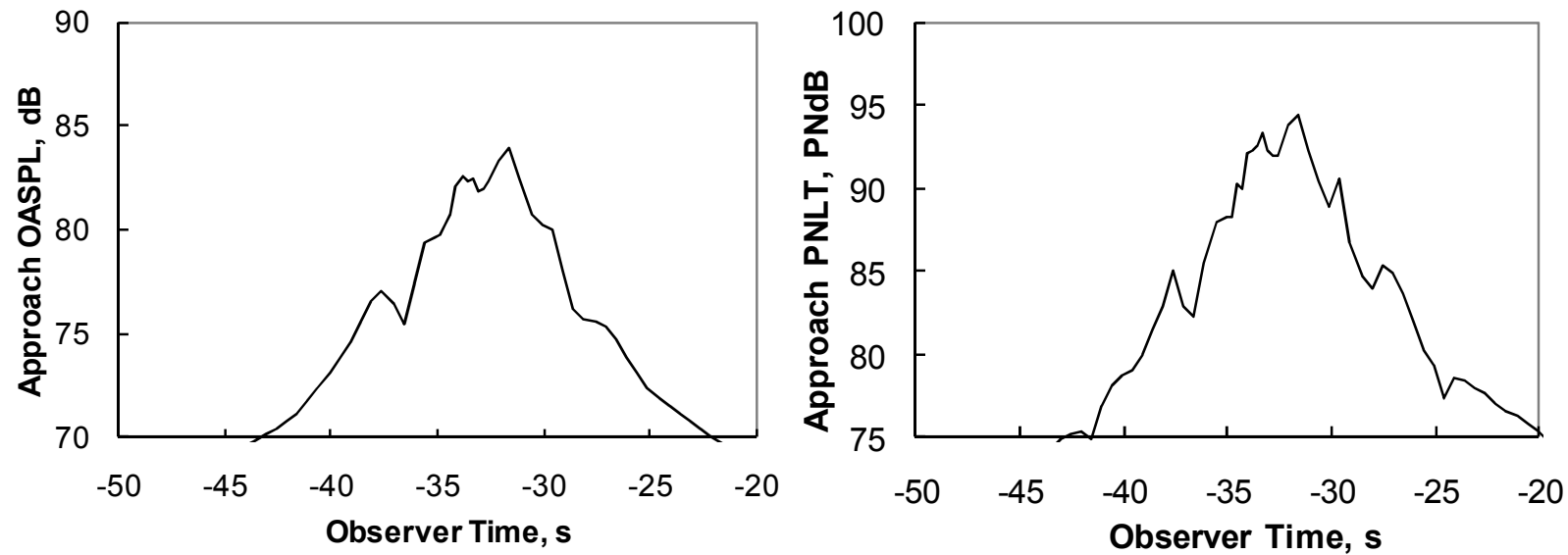

Figure 10. Open rotor approach observer OASPL noise-time history (left), and PNLT noise-time history (right).
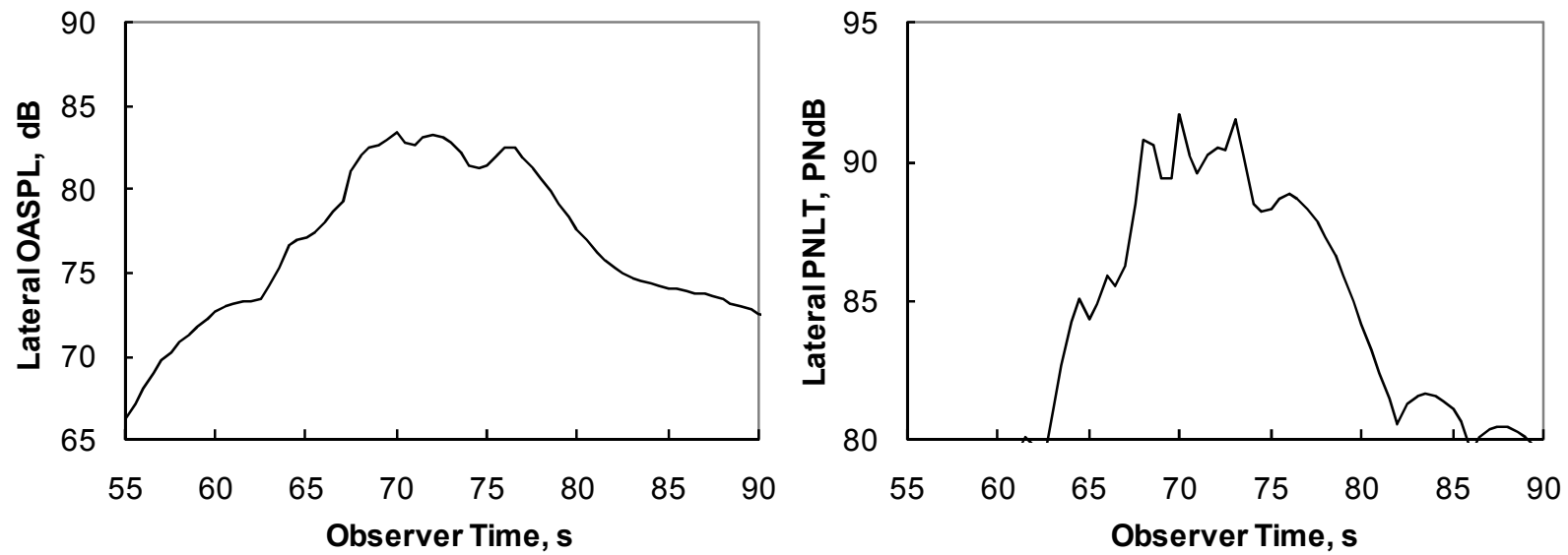

Figure 11. Open rotor lateral observer OASPL noise-time history (left), and PNLT noise-time history (right).
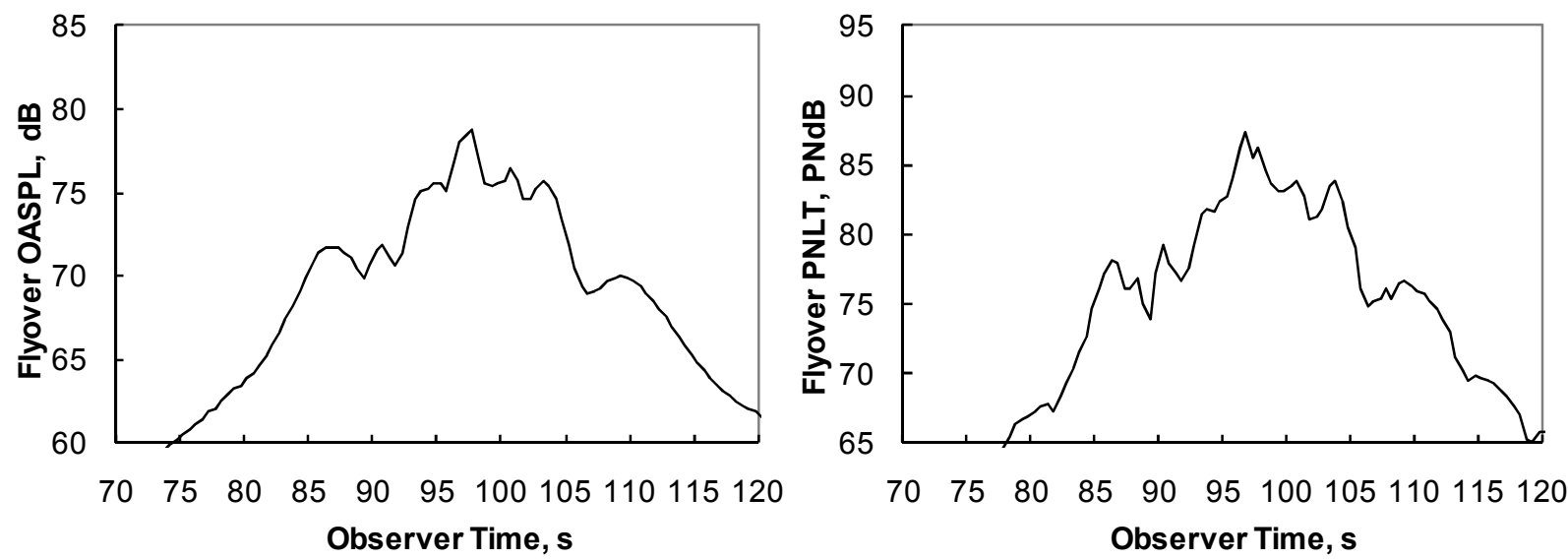

Figure 12. Open rotor flyover observer OASPL noise-time history (left), and PNLT noise-time history (right).

Additional PNLT time histories are computed from available scaled test article spectra measured at other shaft speeds and angles of attack. EPNLs are computed for each available wind tunnel dataset and characteristic curves are constructed of EPNL vs. shaft speed and angle of attack for each observer. The final EPNLs are interpolated from these characteristic curves using the actual throttle settings and angles of attack determined in the trajectory 
analysis. This approach is preferred over interpolating the measured spectra across power setting and angle of attack and proceeding with a direct EPNL calculation. Spectral interpolation is generally a poor practice, since artifacts of interpolation may incorrectly diminish tone content.

The computed lateral, flyover, and approach EPNLs for a notional open rotor powered vehicle are shown in Table 3 with the corresponding Stage 3 limits for an airplane having a maximum takeoff gross weight of 151,000 lb. (Note: The noise analysis presented here was performed in parallel with the aircraft sizing discussed previously and is based on a slightly larger, higher thrust open rotor vehicle.) For Stage 4 noise certification, the maximum noise level permitted at an individual measurement point is the same as the Stage 3 maximum level. However, Stage 4 aircraft are required to have a margin to Stage 3 of at least 2 EPNdB for any two measurement points combined and a cumulative margin to Stage 3 (all three measurement points combined) of not less than 10 EPNdB. Additionally, "trading" EPNL margins between measurement points is no longer permitted. As shown in Table 3, the computed noise levels with the F31/A31 rotor set would meet the Stage 4 requirements with a cumulative margin to Stage 4 of 5.7 EPNdB (10 EPNdB less than Stage 3 margin of 15.7 EPNdB). These results are for demonstration purposes only and are not the noise levels expected for an advanced technology open rotor powered aircraft. Advanced, low-noise rotor designs and innovative noise mitigation strategies which are currently being researched should reduce the certification noise levels.

Table 3. Computed F31/A31 Rotor Set Noise Levels and Certification Limits for a 151,000 lb Aircraft

\begin{tabular}{|l|c|c|c|}
\hline & Computed Value & Stage 3 Limit & Stage 3 Margin \\
\hline Lateral $(\mathrm{EPNdB})$ & 92.8 & 96.5 & 3.7 \\
\hline Flyover $(\mathrm{EPNdB})$ & 87.6 & 91.0 & 3.5 \\
\hline Approach $(\mathrm{EPNdB})$ & 91.7 & 100.3 & 8.6 \\
\hline Cumulative $(\mathrm{EPNdB})$ & 272.1 & 287.8 & 15.7 \\
\hline
\end{tabular}

The open rotor acoustic data used to compute the EPNLs were isolated (i.e., they were collected in the tunnel facility without the presence of a simulated engine pylon, aft fuselage, or tail). Additional sources such as core noise, core jet noise, and airframe noise are not modeled in the above EPNL calculations. Since this paper is intended only to describe the analytical process of evaluating open rotor vehicles, system corrections for these effects were not made. In future assessments, core, jet, and airframe sources will be modeled using the ANOPP methods described in Refs. 39, 40, and 41, respectively. Additional experimental data have been collected with the rotors in the presence of an engine pylon, a simulated fuselage, and at various angles of attack and thus system corrections may be made for these effects as well.

\section{Recommendations for Future Work}

The methodologies and results presented here are just the first steps in re-establishing NASA's capability to reliably evaluate open rotor based aircraft designs. Continued work in several areas is key to reaching the desired capability.

- The performance and acoustic analyses described in this paper utilized different rotor designs due to the limited availability of performance and/or acoustic experimental data from which to build analytical models. Furthermore, the data used are for historical rotor designs which do not reflect the recent advances in performance and acoustic signature that have been accomplished through modern design techniques and continued research. Performance and acoustic models need to be developed incorporating the latest experimental data for modern blade geometries.

- Open rotor performance and noise characteristics are more sensitive to installation effects than traditional turbofan engines. Although in the current process installation effects can be accounted for with simple adjustments, focused, detailed analysis is required to capture installation effects more completely.

- To determine the true benefits and penalties of the open rotor architecture, comparison needs to be made to an equivalent technology turbofan configuration. The $40 \%$ fuel reduction benefit found in this initial analysis is not due solely to the open rotor engine concept. Fuel consumption reductions of $\sim 30 \%$ relative to 1990s technology have been found for advanced turbofan engines on an advanced technology airframe. ${ }^{17}$ However, the airframe and mission assumptions for study described in Ref. 17 are not the same as for this initial open rotor analysis. Additional work is needed to perform a true "apples-to-apples" comparison between advanced turbofan and open rotor configurations.

- The methods and processes described here are reliant on experimental data for existing blade designs. Ultimately, the ability to independently design and analyze new blade geometries is desired so that trade-

14

American Institute of Aeronautics and Astronautics 
offs in performance, weight, and noise can be made. This is particularly important for NASA to be able to evaluate the benefits of open rotor propulsion for applications different than those currently being targeted by engine manufacturers.

\section{Conclusions}

An initial capability to assess and evaluate aircraft configurations with open rotor propulsion has been reestablished at NASA. Processes for modeling engine performance, aircraft system level performance, and certification noise characteristics have been exercised for some initial concepts. At present, this capability relies heavily on the availability of experimental data for existing rotor designs. Even though open rotor engines are heavier and require airframe accommodations such as additional noise insulation which further increase weight, when applied to an advanced single-aisle airframe the increase in propulsive efficiency results in large reductions in fuel consumption. The lighter, smaller vehicle resulting from lower fuel weight for the open rotor designs combined with large reductions in TSFC at takeoff and climb conditions leads to even greater reductions in landing-takeoff $\mathrm{NO}_{\mathrm{X}}$ emissions. Initial noise analysis based on early 1990s blade design technologies indicates a cumulative noise margin of 6 EPNdB relative to Stage 4 regulatory limits. Newer, noise-optimized blade designs should have lower noise levels. Although an initial capability has been established and initial results obtained, additional development work is necessary to make NASA's open rotor system analysis capability on par with existing turbofan analysis capabilities.

\section{Acknowledgments}

The authors would like to thank the Subsonic Fixed Wing Project of NASA's Fundamental Aeronautics Program for supporting this study.

\section{References}

${ }^{1}$ Ethell, J. L., "Fuel Economy in Aviation," NASA SP-462, 1983.

${ }^{2}$ Bowles, M. D., “The ‘Apollo' of Aeronautics: NASA's Aircraft Energy Efficiency Program 1973-1987,” NASA SP-2009574, 2010.

${ }^{3}$ Norris, G., "Open Return: General Electric and NASA dust off test rigs from 20 years ago," Aviation Week and Space Technology, 14 July 2008.

${ }^{4}$ Norris, G., "Rig Rolling: Wing tunnel test imminent for Rolls's open rotor rig," Aviation Week and Space Technology, 14 July 2008.

${ }^{5}$ Conlon, J. A., and Bowles, J. V., “Application of Advanced High Speed Turboprop Technology for Future Civil Short-Haul Transport Aircraft Design," AIAA 78-1487, 1978.

${ }^{6}$ Blythe, A. A., and Smith, P., "Prospects and Problems of Advanced Open Rotors for Commercial Aircraft," AIAA 85-1191, 1985.

${ }^{7}$ U.S. Code of Federal Regulations, Title 14, Chapter I, Part 36. Noise Standards: Aircraft Type and Airworthiness Certification.

8“Current Market Outlook 2010-2029,” Boeing Commercial Airplanes. 2010.

${ }^{9}$ Claus, R.W.; Evans, A.L.; Lytle, J.K., and Nichols, L.D.: "Numerical Propulsion System Simulation," Computing Systems in Engineering, Vol. 2, No. 4, pp. 357-364, 1991.

${ }^{10}$ NPSS User Guide Software Release: NPSS 1.6.3 AL.

${ }^{11}$ NPSS Reference Sheets Software Release: NPSS_1.6.3 AL.

${ }^{12}$ Onat, E., and Klees, G., "A Method to Estimate Weight and Dimensions of Large and Small Gas Turbine Engines," NASA CR 159481, 1979.

${ }^{13}$ Tong, M.T., Halliwell, I., and Ghosn, L.J., "A Computer Code for Gas Turbine Engine Weight and Life Estimation,” ASME Journal of Engineering for Gas Turbine and Power, Vol. 126, No. 2, pp. 265-270, April 2004.

${ }^{14}$ Tong, M.T., and Naylor, B.A., “An Object-Oriented Computer Code for Aircraft Engine Weight Estimation," GT200850062, ASME Turbo-Expo 2008, June 2008.

${ }^{15}$ Guynn, M. D., Berton, J. J., Fisher, K. L., Haller, W. J., Tong, M. T., and Thurman, D. R., "Engine Concept Study for an Advanced Single-Aisle Transport,” NASA TM-2009-215784, 2009.

${ }^{16}$ Hendricks, E. S., "Development of an Open Rotor Cycle Model in NPSS using a Multi-design Point Approach," GT201146694, ASME Turbo-Expo 2011, June 2011.

${ }^{17}$ Guynn, M. D., Berton, J. J., Fisher, K. L., Haller, W. J., Tong, M. T., and Thurman, D. R., "Refined Exploration of Turbofan Design Options for an Advanced Single-Aisle Transport," NASA TM-2011-216883, 2011.

${ }^{18}$ Mann, S. A. E., and Stuart, C. A., “Advanced Propulsion through the 1990s: An Airframer's View,” AIAA-85-1192, 1985.

${ }^{19}$ McCullers, L., "Aircraft Configuration Optimization Including Optimized Flight Profiles," Proceedings of the Symposium on Recent Experiences in Multidisciplinary Analysis and Optimization, NASA CP 2327, April 1984. 
20“MD-90-30 Airplane Characteristics for Airport Planning,” MDC K9099, Boeing Commercial Airplanes, October 2002.

${ }^{21}$ Hopkins, H., "Powerfully Quiet: The McDonnell Douglas MD-90 is likely to meet any Stage 4 requirements," Flight International. October 26-November 1, 1994.

${ }^{22}$ Ardema, M. D., Chambers, M. C., Patron, A. P, Hahn, A. S., Miura, H., and Moore, M. D., "Analytical Fuselage and Wing Weight Estimation of Transport Aircraft," NASA TM 110392, May 1996.

${ }^{23}$ Henne, P. A., "MD-90 Transport Aircraft Design," AIAA-89-2023, 1989.

${ }^{24}$ Whitfield, C. E., Mani, R., and Gliebe, P. R., "High Speed Turboprop Aeroacoustic Study, (Counterrotation), Volume I Model Development," NASA CR 185241, July, 1990.

${ }^{25}$ Whitfield, C. E., Mani, R., and Gliebe, P. R., "High Speed Turboprop Aeroacoustic Study, (Counterrotation), Volume II Computer Programs," NASA CR 185241, July, 1990.

${ }^{26}$ Majjigi, M.; and Wojno, J., "Previous Open Rotor Noise Experience at GE," General Electric Presentation, X-Noise Open Rotor Technology Seminar, Lausanne, Switzerland; March 18, 2011.

${ }^{27}$ NASA Press Release (Vol. 2, Issue 3, March 30, 2009): GE and NASA Partner on Open Rotor Engine Testing, URL: http://www.nasa.gov/offices/oce/appel/ask-academy/issues/volume2/AA_2-3_F_ge_rotor.html [cited 4/8/2011].

${ }^{28}$ Elliott, D. M., "Initial Investigation of the Acoustics of a Counter Rotating Open Rotor Model With Historical Baseline Blades in a Low Speed Wind Tunnel," $17^{\text {th }}$ AIAA/CEAS Aeroacoustics Conference (32 ${ }^{\text {nd }}$ AIAA Aeroacoustics Conference), AIAA 2011-2760, June, 2011.

${ }^{29}$ Hager, R. and Vrabel, D., “Advanced Turboprop Project,” NASA SP-495, April, 1988.

${ }^{30}$ Hoff, G., et al., "Experimental Performance and Acoustic Investigation of Modern, Counterrotating Blade Concepts," NASA CR-185158, Jan., 1990.

${ }^{31}$ Delaney, B.R., Balan, C., West, H., Humenik, F.M., and Craig, G., “A Model Propulsion Simulator for Evaluating Counter Rotating Blade Characteristics," SAE Paper 861715, Aerospace Technology Conference and Exposition, Long Beach, CA, Oct. 13-16, 1986.

${ }^{32}$ Berton, J. J., "Empennage Noise Shielding Benefits for an Open Rotor Transport,” AIAA 2011-2764, 2011.

${ }^{33}$ Gillian, R.E., “Aircraft Noise Prediction Program User's Manual,” NASA TM-84486, 1983.

${ }^{34}$ Zorumski, W.E., "Aircraft Noise Prediction Program Theoretical Manual," NASA TM-83199, 1981, Parts 1 and 2 (Currently maintained at NASA Langley Research Center by the ANOPP team in electronic format and provided upon request; Latest revision: April, 2011).

${ }^{35}$ Rawls, J., “ACD Module,” ANOPP Theoretical Manual, ver. 29, NASA Langley Research Center, Hampton, VA, 2011.

${ }^{36}$ U.S. Code of Federal Regulations, Title 14, Chapter I, Part 25. Airworthiness Standards: Transport Category Airplanes.

${ }^{37}$ Stuart, A. R., "The Unducted Fan Engine," AIAA-85-1190, 1985.

${ }^{38}$ U.S. Code of Federal Regulations, Title 14, Chapter I, Part 34. Fuel Venting and Exhaust Emission Requirements for Turbine Engine Powered Airplanes.

${ }^{39}$ Emmerling, J.J., Kazin, S.B., and Matta, R.K., "Core Engine Noise Control Program. Volume III, Supplement 1 - Prediction Methods," FAA-RD-74-125, III-I, Mar. 1976 (Available from DTIC as AD A030 376.)

${ }^{40}$ Stone, J.R., Krejsa, E.A., Clark, B.J., and Berton, J.J., "Jet Noise Modeling for Suppressed and Unsuppressed Aircraft in Simulated Flight," NASA TM-2009-215524, 2009.

${ }^{41}$ Fink, M.R., “Airframe Noise Prediction Method,” FAA-RD-77-29, March, 1977. 